\title{
SOBRE JORGE DE MONTEMAYOR, POETA Y CANTOR EN LA CORTE ESPAÑOLA*
}

Francisco Miguel Ruiz Cabello

\begin{abstract}
In the current article, we search in the importance of the musical aspect of the Diana' author, Jorge de Montemayor, considering that he used the music to sustain himself until 1552 and he arrive to be a singer in the chapel of Carlos V's daughters. With the musicological approach we want remark, not only the well know influence of the music in his play, but also give the necesary historical sense to his biography in order to suggest new ways to study this portuguese poet.
\end{abstract}

En el presente artículo indagamos en la importante faceta musical del autor de La Diana, Jorge de Montemayor, considerando que se sirvió de la música para subsistir al menos hasta 1552 y que llegó a ingresar como cantor en la capilla de las hijas de Carlos V. Mediante el enfoque musicológico no sólo deseamos incidir en la reconocida influencia de la música en su obra, también pretendemos dar a su biografía la necesaria contextualización histórica; de forma que puedan surgir nuevas líneas de investigación para el estudio de este poeta portugués.

En conjunto, no son muchas las noticias que tenemos del celebrado autor de La Diana. A pesar de ello, su biografía se ha podido trazar sobre la base de su testimonio personal, la correspondencia poética con otros destacados autores, a partir de sus obras y, en una mínima parte, por evidencias documentales. Nada sabemos cierto de su familia ni de su formación, así como resultan vagas las noticias de sus últimos años y temprana muerte. Sí se puede afirmar que tuvo una vida caracterizada por un desplazamiento continuo: su nacimiento puede fecharse entre 1520 y 1525 en Montemôr-o-Velho, población cercana a Coimbra de la que el poeta toma el nombre; estuvo en la corte española como cantor y volvió a Portugal, aunque por poco tiempo, como aposentador de doña Juana, la hija menor de Carlos V; posteriormente no sabemos si siguió a Felipe II hasta Inglaterra, aunque todo parece indicar que estuvo en Flandes como soldado antes de pasar a Valencia buscando la protección de la nobleza. Las últimas

\footnotetext{
* Quisiera expresar mi reconocimiento y gratitud a Juan Montero Delgado, profesor titular del Departamento de Literatura española de la Universidad de Sevilla, por toda la valiosa información que me ha facilitado y por la revisión de este trabajo. El agradecimiento lo hago extensivo a María Isabel Osuna Lucena, profesora titular del Departamento de Historia del Arte de la Universidad de Sevilla y directora de la Cátedra "Cristóbal de Morales", por sus prácticos y acertados consejos.
} 
referencias de su vida las encontramos en Italia hacia 1561, donde algunas noticias localizan su muerte en el Piamonte y debido a cierta pendencia por amores ${ }^{1}$.

El singular mérito atribuido a Jorge de Montemayor de lograr ser reconocido como poeta sin contar con grandes estudios se hizo proverbial, así lo comenta Miguel Sánchez de Lima: "Y a lo que algunos dizen que la Poesía se adquiere con el estudio de las letras, y que de otra manera no puede ninguno ser Poeta, yo respondo que Montemayor fue un hombre de grandíssimo natural, porque todo lo que hizo fue sacado de allí, pues se sabe que no fue letrado ni más de romancista" 2 . La falta de estudios académicos habría quedado compensada, de esta forma, con una extraordinaria inquietud intelectual y con un elevado ingenio, pues a través de sus escritos podemos apreciar que el portugués poseía un bagaje cultural de cierto nivel que le permitió desenvolverse con brillantez en el campo literario (las referencias de autores clásicos en sus obras insinúan, además, que tuvo que tener un contacto suficiente con esta literatura, si no a través del latín, sí mediante traducciones), practicar profesionalmente la música y, aunque con menor destreza, departir en temas teológicos ${ }^{3}$. A ello habría que sumar su dominio de varias lenguas, si bien esta condición estaría dispuesta por las circunstancias históricas. Además de su lengua natural portuguesa, del castellano, del italiano y del latín más o menos al uso, supo defenderse en catalán y traducir así los Cantos de amor de Ausias March (Valencia 1560)4.

\footnotetext{
${ }^{1}$ Para un resumen de su biografía, véase la introducción de J. de Montemayor, Los siete libros de la Diana, eds. F. López Estrada y Mª T. López García-Berdoy (Madrid 1993). Una buena síntesis y exposición de las diversas hipótesis y del estado actual de la cuestión se puede encontrar en $\mathrm{B}$. Creel, The religious poetry of Jorge de Montemayor (Londres 1981). Para un mayor acercamiento a este autor partiendo de su famosa novela, véase la excelente edición crítica J. de Montemayor, La Diana, ed. Juan Montero, est. prel. de J.B. Avalle-Arce (Barcelona 1996).

${ }^{2}$ M. Sánchez de Lima, El Arte poético en romance castellano, ed. Rafael de Balbín Lucas (Madrid 1944) 37-38.

3 Algunos de sus libros demuestran que Montemayor tenía una apreciable cultura bíblica, junto a un discurso teológico recogido de Pedro Lombardo que trató con no demasiada suficiencia. En el prólogo de su obra Diálogo espiritual, escrita cuando servía en la Corte española, advierte al lector: "Si te parece cossa digna de reprehensión que un hombre sin hedad ni esperiencia pretenda tractar matherias tan difficultosas y $\tan$ differentes de mi profhesión y ábito ten entendido que puesto casso que resido en palacio entre cavalleros y damas no en monasterio entre religiosos y theólogos nunca esto ha sido parte para estorvarme el exercicio y lection de la sagrada escriptura a quien desde mi niñez he sido afficionado" (cf. Creel, op. cit., 58-59). Sobre la relación de Montemayor con la Inquisición española por la influencia en sus obras de Savonarola y de Erasmo véase M. Bataillon, Erasmo y España. Estudios sobre la historia espiritual del siglo XVI (México 1956) 607-608; también el capítulo VI del citado estudio de Bryan Creel, dedicado a las obras de Montemayor incluidas en el Indice de libros prohibidos por la Inquisición del año 1559 y la introducción a J. de Montemayor, Poesía completa, ed. de J.B. Avalle-Arce, con la colaboración de E. Blanco (Madrid 1996).
}

${ }^{4}$ En el "Soneto de un cavallero valenciano a Iorge de Montemayor", que encabeza la edición de dicha traducción, se advierte: "La empresa fue de ingenio al mundo raro,/ qual le pedía la aspereça fiera/ de la escabrosa lengua Lemosina./ Y aquí Montemayor muestra bien claro, que esperiencias de Amor le abren carrera,/ por do solo él tan fácil se encamina" (A. March, Las obras de Ausias March. Traducidas por Jorge de Montemayor, ed. de F. Carreras de Calatayud (Madrid 1947) 7). 
Aunque Montemayor no llegara a tener una formación universitaria, y sin negar tampoco una más que probable ascendencia humilde 5 , quizá sí tuvo acceso a una educación cortesana o eclesiástica. A este respecto, existe una hipótesis que ve al poeta en estrecho trato con los linajes lusitanos de los Paíva y los Pina ${ }^{6}$. La referencia a tales familias aparece en las estrofas iniciales de un poema de Montemayor titulado Historia de Alcida y Silvano, incluido en su Segundo Cancionero (Amberes 1558), que se considera autobiográfico:

Debajo de altos pinos muy umbrosos,
con los de Pina siempre conversaba,
cuyo linaje y hechos generosos
al son de su zampoña los cantaba.
Y los de Paíva allí por muy famosos
sus virtudes heroicas celebraba,
llorando a dos Antonios, cuya suerte
muy de presto la atajó la cruda muerte (vv. $57-64)^{7}$

Siguiendo esta línea, es interesante observar que en el Monasterio de Santa Cruz de la ciudad de Coimbra, centro musical de primer orden durante los siglos XVI y XVII, destacó Dom Heliodoro de Paíva (n.1502; m. en Coimbra 20-XII-1552). Este importante compositor "crúzio", hermano de leche del rey Juan III y posible mentor musical de sus hijos, además de humanista versado en lenguas clásicas, iluminador y pintor, "era cantor, \& musico mui destro, \& contrapontista (...) tangia orgâo, craviorgâo cô notavel ar, \& graça; tangia viola de arco, \& tocava harpa, \& cantava a ella com tanta suavidade, que enlevava os ouvintes" 8 . ¿Llegó Jorge de Montemayor a relacionarse con tan erudito representante de los Paíva en la corte o en el cercano e influyente centro monástico? Sería tentador atribuirle al destacado músico los conocimientos humanísticos y musicales que portara el poeta, pero sólo es un supuesto a tener en cuenta, sin más pruebas que las puramente circunstanciales.

Nuestro autor supo complementar desde muy joven su disposición hacia las letras con la práctica de la música, ejerciendo como cantor profesional ante la necesidad de mantenerse. La epístola que escribiera a su amigo, el importante poeta portugués Francisco Sá de Miranda (fechable entre 1552 y 1553), recoge estas confesiones de su propia mano, junto con la decisión de pasar a la "gran Hesperia" en busca de nuevas y mejores oportunidades:

\footnotetext{
5 Sobre la supuesta familia de Montemayor, con un origen hispano-judio y condición de "conversos", véase Creel, op. cit., 45-46 y 54; también M. Bataillon, "Melancolía renacentista o melancolía judía", Varia lección de clásicos españoles (Madrid 1964).

${ }^{6}$ La hipótesis está recogida por G. Schönherr, Jorge de Montemayor: Sein Leben und Sein Schäferroman, die «Siete libros de la Diana» (Halle 1886) 9-27 (cf. Creel, op. cit., 45, nota 11).

${ }^{7}$ E. Rhodes, "Edición de la Historia de Alcida y Silvano, poema de Montemayor", Dicenda, II (1983) 205. La identificación de tales "Antonios" aún no ha podido ser aclarada.

${ }^{8}$ M.C. de Brito y L. Cymbron, Historia da música portuguesa (Lisboa 1991) 43-44.
} 


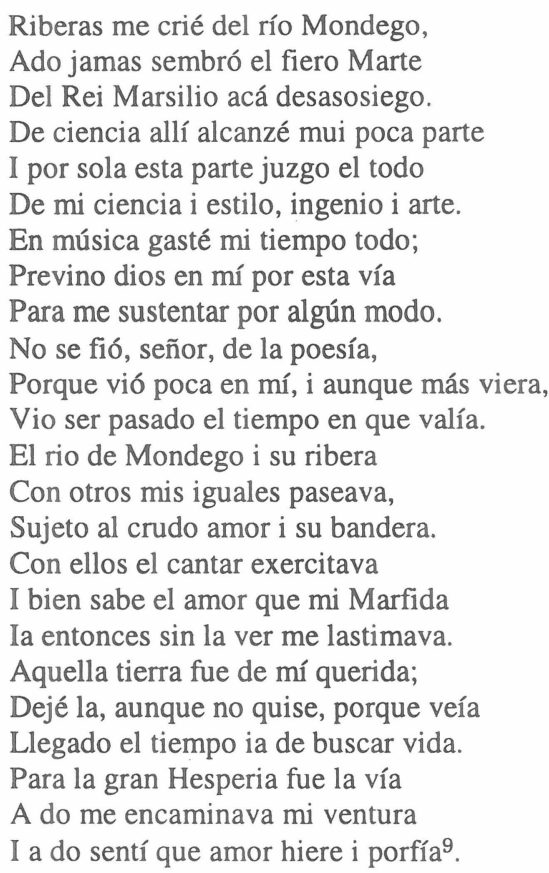

Atendiendo a este testimonio de la epístola a Francisco Sá de Miranda y su trayectoria como músico, es de suponer que Montemayor llegara a perfeccionar su canto a base de experimentar la polifonía en alguna capilla musical portuguesa. Tradicionalmente se venía admitiendo que el poeta tuvo que servir como cantor en la capilla de la hija de Juan III de Portugal, doña María Manuela, y que la boda de esta princesa con el entonces príncipe Felipe II (celebrada en Salamanca el 14 de Noviembre de 1543) hubo de ser la mejor ocasión para vincularse con la corte de los Austria ${ }^{10}$. No obstante, de haber participado en

9 C. Michaëlis de Vasconcelos, Poesías de Francisco Sá de Miranda (Halle 1885) 654-56. El carácter autobiográfico de esta epístola responde al interés de Montemayor por mostrar una trayectoria acorde con sus aspiraciones como poeta, reclamando así el reconocimiento en el mundo de las letras. Es aquí donde Montemayor busca sus verdaderas expectativas para conseguir prestigio social, aunque en el texto lo exprese con falsa modestia. La música se presenta, pues, como un socorrido recurso para subsistir. Véase J. Montero, "Montemayor y sus corresponsales poéticos (con una nota sobre la epístola a mediados del siglo XVI)", en La epístola, ed. B. López Bueno (Sevilla 2000) 188-189.

${ }^{10}$ Dicho argumento se basaba originariamente en una Lamentación que escribiera Montemayor al morir la princesa en Julio de 1545 del parto del príncipe don Carlos, titulada Glosa de diez coplas de don Jorge Manrique hecha por Jorge de Monte moor; sobre la muerte de la muy alta princesa doña María hija del Rey don Juan tercero de Portugal; dirigidas al muy magnífico y discreto señor Juan da Silva, Regidor de Portugal (editada en Creel, op. cit., 246-256). Sin embargo, la misma obra da a entender, por la forma en que aparece redactada, que Montemayor aún continuaba en Lisboa cuando sucedió el óbito (Creel, op. cit., 47). El lugar de edición de la Glosa no se puede asegurar, pero es posible que fuese en España, dada la proximidad entre la fecha de la muerte de la princesa y el primer testimonio de la presencia del escritor en estas tierras (véase la nota 15). En todo caso, sí podría aceptarse que Montemayor hubiera sido testigo de la salida del suntuoso cortejo que llevaba a la princesa María Manuela hasta España en Octubre de 1543, pues en la Glosa se sitúa como espectador de aquel acontecimiento y en la Copla octava ofrece muestras de la veracidad histórica de lo que relata cuando alude a los Infantes don Luis (m. 1555) y don 
dicho evento principesco, no pudo hacerlo al servicio de doña María Manuela pues -como ya notara Carolina Michaëlis de Vasconcelos- la formación musical que la acompañó con motivo de su boda hasta llegar finalmente a Valladolid, donde se encontraba la Corte, era exclusivamente instrumental ${ }^{11}$. La única opción donde ubicar a un cantor que hubiese tomado parte en la comitiva portuguesa que entró en España era la capilla del Arzobispo de Lisboa, don Fernando de Vasconcellos: "el arçobispo de Lisboa, con onrrada casa, buena capilla y escoxidos cantores" 12 , pues las demás personalidades portuguesas no pasaron la frontera. Este prelado regresó a Lisboa desde Valladolid a mediados de Diciembre, junto con parte de la Casa de la princesa: "El Sermo. Rey de Portugal scrivió al arçobispo de Lisboa que luego se partiesse, y assí lo hizo (...). Bolbiéronse con él y antes muchos reyes d'armas, trompetas, atabales y ministriles, moços de cámara y otras gentes que vinieron con la princesa; repartióseles a todos estos hasta seicientos ducados"13.

La ausencia de noticias hace que no podamos confirmar ni desmentir una relación de Jorge de Montemayor con el Arzobispo de Lisboa o con la corte portuguesa en el plano musical y, hasta el momento, nada permite asegurar tal práctica profesional de la música con anterioridad a su puesto de cantor en la capilla de las hijas de Carlos V. En todo caso, de lo que no hay duda es que debe descartarse el año 1543 como la fecha de su ingreso en

Enrique (1512-1580), hermanos del rey Juan III: "Los infantes vuestros tíos/ que os fueron acompañar al partir,/ con vuestra muerte están fríos,/ no sabiendo qué pensar ni decir".

11 "[La princesa traía] doçe menestriles altos y diez y seis trompetas con una librea amarilla y dos faxas de raso açul" (Recebimiento que se hizo en Salamanca a la princesa Doña María de Portugal, viniendo a casarse con el príncipe Don Felipe $2^{\circ}$, Biblioteca Nacional de Madrid, Ms. 4013, f. 31 r.); "Era tanto el numero de menestriles de la una parte y otra que apenas oyr se podían unos a otros. los menestriles y tronpetas y atabales de la prinçesa y del duque [de Medina-Sidonia] yvan por orden. Todos los de la prinçesa yvan de terciopelo leonado" (R. Costés, "Le mariage de Philippe II et de l'infante Marie de Portugal: Relation d'Alonso de Sanabria, évéque de Drivasto", Bulletin Hispanique, XVII (1915) 29. Traslado del Manuscrito 107, II, 4 de la Biblioteca de El Escorial).

12 Costés, op. cit., 27. En el Manuscrito 4013 de la Biblioteca Nacional de Madrid se indica lo siguiente: "Hayan así mismo una capilla de cantores raçonables y muchos menestriles altos y baxos" (f. 31 v.). Este Manuscrito induce a error pues dicha noticia aparece después de la descripción de los ministriles de la princesa María Manuela sin concretar a quién pertenecía. La Relación de Alonso de Sanabria aclara suficiéntemente que la única capilla musical presente servía al Arzobispo de Lisboa.

13 J.M. March, Niñez y juventud de Felipe II: Documentos inéditos sobre su educación civil, literaria y religiosa y su iniciación al Gobierno (1527-1547). Vol. II (Madrid 1941): Carta de Francisco de los Cobos a Carlos V, 4 de Febrero de 1544, Archivo General de Simancas, Estado-Castilla, Leg. 68, ff. 351-358. Existe una excelente crónica del viaje que realizó el Arzobispo de Lisboa acompañando a la princesa María Manuela, escrita por un miembro anónimo de su comitiva (seguramente un clérigo), aunque por desgracia no se encuentran en ella datos que puedan precisar más los que aquí citamos. Lleva por título Lembrança da ida que fez o Muito Illustre e Reverendissimo Senhor D. Fernando de Meneses e Vasco Gomcelos Arcebispo de Lisboa com a muito esclarecida Ifante D. Maria Primcesa de Castella filha del Rej D. Joam de Portugal o terceiro deste nome e da Rainha D. Catherina sua molher levando-a ao Principe de Castella seu marido por nome D. Felipe filho do Emperador D. Carlos o quinto deste nome no anno de 1543. no mes de Outrubro da dita era (A.C. de Sousa Viterbo, Provas da Historia Genealógica da Casa real portuguesa, eds. M. Lopes de Almeida y C. Pegado. Tomo III. 1ª parte (Coimbra 1948) 141-210). 
la corte española, pues así se deduce de los datos que aportan los documentos de la Casa Real ${ }^{14}$.

Otros indicios vienen a situarle en España muy poco después de la muerte de la primera mujer de Felipe II. Concretamente, Montemayor pudo pasar por Sevilla, según se desprende de un soneto del poeta Gutierre de Cetina incluido en el Cancionero de Jorge de Montemayor del año 1554 en que se le despide antes de partir hacia "la ribera del hermoso Pisuerga": "De Gutierre de Cetina siendo enamorado en la Corte para donde Montemayor se partía" y "Respuesta de Jorge de Montemayor siendo enamorado en Sevilla donde Gutierre de Cetina se quedava"15.

Es con fecha de 7 de Diciembre de 1546 cuando vieron la luz en Sevilla los Tres libros de Música en cifras para vihuela del músico y canónigo de la catedral hispalense Alonso de Mudarra (c.1510-1580). Una de las piezas que se incluyen es un lamento por la muerte de la princesa María Manuela de Portugal titulado "Qué llantos son aquestos", para voz y vihuela de mano, cuya melodía está relacionada con el tema de cabeza de un Tiento de IVo tono de Heliodoro de Paíva. Para el musicólogo M.S. Kastner, es posible que Mudarra, al aludir de este modo a quien pudo ser el maestro de la princesa, quisiera honrarla recordando la excelente preparación musical de la que hacía gala y daban fe los coetáneos ${ }^{16}$. Este hecho nos habla de la existencia de ciertas relaciones musicales entre Mudarra y Paíva, relaciones en las que, me atrevo a sospechar, pudo estar involucrado el poeta.

La presencia de unos versos laudatorios de Montemayor en la obra de F. de Trasmiera Vida y excelencias de la...Virgen, publicada en Valladolid en 1546, es un dato significativo que bien pudiera enlazarse con su partida hacia la Corte desde Sevilla, como afirma Gutierre de Cetina en aquel soneto. Pero lo que de verdad sugieren tales versos es el establecimiento del portugués en España contando con una presumible antelación a su

\footnotetext{
14 Como anticipo y complemento de los datos que indicamos más adelante, ya Carolina Michaëlis de Vasconcelos pudo comprobar que el nombre de Jorge de Montemayor no aparecía con anterioridad a 1545 en la "Libranza de descargo y satisfacción que se hizo a los criados de su alteza [la princesa María Manuela de Portugal]" (Archivo General de Simancas, Casa Real, Leg. 44-50). Tampoco consta Montemayor en los "Alvalaes del juro de por vida que se dieron a los criados de la princesa, que aya gloria, en cumplimiento de los que dexó hordenado en su testamento" (N. Alonso Cortés, "Sobre Montemayor y La Diana", Boletín de la Real Academia Española, XVII (1930) 353).
}

${ }^{15}$ Francisco López Estrada no duda en afirmar que Jorge de Montemayor conocía Sevilla y que en La Diana -donde pueden rastrearse alusiones al habla andaluza- se hace referencia a esta ciudad al emplear el nombre de Soldina como villa de la provincia de Vandalia (término clásico que se aplicaba a Andalucía). En lo relativo al encuentro entre los dos poetas, Begoña López Bueno también se inclina por las mismas fechas (entre 1545 y 1546) al advertir que -dado el trasiego viajero entre Italia y las Indias de Gutierre de Cetina- "su paso por Sevilla en 1545-46 debió ser, pues, muy rápido. Parece posible situar en este momento el Soneto que dirige a Jorge de Montemayor" (B. López Bueno, Gutierre de Cetina, poeta del Renacimiento español (Sevilla 1978) 68).

16 M. Santiago Kastner, Antonio de Cabezón (Burgos 2000) 180. Véase también M.S. Kastner, "Orígenes y evolución del tiento para instrumentos de tecla", Anuario Musical, XXVIII-XXIX (1973-1974) 32. 
ingreso en la capilla musical de las Infantas, hecho éste que se produjo sin que se constate mediación de otra capilla o Casa alguna ${ }^{17}$.

Sólo encontramos datos verificables documentalmente de la estancia castellana de Jorge de Montemayor a partir de su entrada al servicio de las Infantas doña María (1528-1603) y doña Juana (1535-1573). Efectivamente, el poeta portugués aparece como cantor en la "Ynformación de otros ciertos oficiales y criados de la $\mathrm{S}^{\mathrm{a}}$ Ynfanta doña Juana que residen en esta corte en servicio de la princesa doña María", donde se anota: "Jorge de Montemayor, cantor, henero sirvió [hasta Julio]"18, y también en la "Nómina de la paga de los ofiçiales y mugeres de la casa de la Señora Ynfanta doña Juana" del último tercio del año 154919. En ambas relaciones de oficiales Montemayor queda asignado a la Casa de la Infanta doña Juana. El hecho de que esta Casa se reconozca como perteneciente sólo a dicha Infanta se debe al matrimonio de su hermana doña María con Maximiliano II de Austria, celebrado en Valladolid el 13 de Septiembre de $1548^{20}$

En Octubre de ese año, Felipe II viajará a Italia, Alemania y Flandes para hacer su presentación oficial en Europa de manos de su padre el emperador Carlos V, quedando Maximiliano y su esposa en España como regentes hasta su vuelta en Julio de 1551. Durante este tiempo, al menos parte de la capilla musical de las Infantas -al servicio exclusivo de doña Juana- servirá también a la ahora princesa doña María en Valladolid, tal y como recoge textualmente la citada "Ynformación" del año 1549.

Seguramente Jorge de Montemayor se incorporó a la capilla de las Infantas en el tiempo comprendido entre mediados de 1547 y principios de 1548, pues así puede interpretarse del frontispicio de una obra que dedicara a la hija mayor de Carlos V, la Exposición Moral sobre el Psalmo LXXXVI del Real propheta David, dirigida a la muy alta y muy poderosa Señora la Infanta Doña María por Jorge de Montemayor Cantor de la Capilla de S.A. Alcalá de Henares, por Juan de Brocar, Imprenta de la Universidad, en $1^{\circ}$ de Marzo de

\footnotetext{
17 Advirtiendo el temprano contacto que pudo tener Montemayor con los círculos cortesanos de Portugal, Juan Montero ofrece la hipótesis de que eso "le sirvió - dada la fluidez de comunicación entre los reinos peninsulares en la época- para acceder luego a los de Castilla" (La Diana, ed. cit., XXVII, nota 1). Es innegable que los portugueses contaban con una destacada presencia en la corte española, atendiendo a una realidad social y cultural compartida entre los dos reinos y realzada políticamente por los acuerdos matrimoniales -se sabe que el poeta dirigió años después una de sus cartas a don Jorge de Meneses, cierto caballero portugués con quien había coincidido en la corte de Castilla (La epístola, op. cit., 184)- pero desconocemos qué grado de incidencia pudo tener dicho factor a la hora de ingresar Montemayor en la Casa de las Infantas.
}

${ }_{18}$ H. Anglés, La música en la Corte de Carlos V (Barcelona 1944) 78. Este documento no está fechado, pero podemos suponer que se refiere al primer tercio del año 1549. La anotación entre corchetes es de Anglés.

19 Ibidem, 78.

${ }^{20}$ La capilla musical de la Casa de las Infantas fue creada en 1539 con músicos que habían pertenecido a la difunta emperatriz Isabel. Su ubicación antes de que se casase la mayor de las hijas de Carlos V fue primero en el castillo de Arévalo, pasando a Alcalá de Henares en el año 1544 (Anglés, op. cit., 72-73). 
154821. Tanto la fecha como el lugar de publicación y el título aún de "Infanta" a doña María sitúan a Montemayor en Alcalá de Henares, donde de hecho se encontraba temporalmente la residencia de las Infantas. A partir de aquí, podemos seguir la pista al poeta hasta la corte vallisoletana, donde lo imaginamos participando, ya en las ceremonias litúrgicas, ya en las fiestas de palacio u otros momentos designados por el protocolo donde era requerida la presencia de los cantores -es preciso recordar que a finales de 1548 también se introdujo en la Corte la etiqueta al estilo de Borgoña por orden de Carlos V, reforma que afectaría de algún modo a las intervenciones de la capilla musical-.

Una vez finalizadas las obligaciones con doña María, los cantores -y con ellos nuestro poeta- debieron de regresar junto a doña Juana, que residía en Toro desde 1550. Allí Montemayor fue adscrito en calidad de aposentador a su séquito ${ }^{22}$ cuando esta Infanta contrajo matrimonio con el príncipe portugués don Juan Manuel de Avís (1537-1554), pasando a Lisboa a finales de 1552 . Ello no descarta el que pudiera continuar como cantor tras la disolución oficial de la Casa de las Infantas al casarse la hija menor de Carlos V, pues la princesa llevó consigo parte de su Capilla de música y la coincidencia de ambas actividades en una misma persona no era nueva en la organización de la Casa ${ }^{23}$. De su servicio en Portugal junto a la princesa doña Juana también nos da noticia el propio Montemayor en la epístola a Francisco Sá de Miranda:

En este medio tiempo la estremada

De nuestra Lusitania gran princeza

En quien la fama siempre está ocupada,

\footnotetext{
${ }^{21}$ En la nómina de la Casa de las Infantas para el primer tercio del año 1547 consta como único cantor contrabajo Lázaro Velázquez que, al parecer, pasó a Toledo y regresó después para ingresar en la capilla del príncipe Felipe con motivo de su viaje a finales de 1548, según la siguiente noticia: "[Hágase título de cantor a] Velázquez, contrabajo de la $S^{a}$ Infante (sic), con XL mill para yr con su Alteza./ Çédula para que se adelante el tercio al contrabajo que viene de Toledo para yr con su Alteza, porque tiene neçesidad" (Anglés, op. cit., 106). Montemayor aparecerá más adelante en el mismo puesto que ocupara Lázaro Velázquez por lo que, además de descubrir la tesitura vocal del autor de La Diana, se deduce que aquella plaza vacante pudo ser la ocasión por la que consiguió incorporarse a la capilla musical de las Infantas.

22 "Jorge de Montemajor tem por meu Aposemtador outro tanto [30.000 reis], e maes lhe haô de dar dez mil reis para ajuda de guasto por alvara meu a parte para que dandolhe satisfaçaô delles os naô aja dahj em diante, e he todo o que ha de haver corenta mil reis" (Sousa Viterbo, op. cit., 94).

${ }^{23}$ Según Sousa Viterbo, el escritor aparece en una relación existente en el Archivo Nacional do Torre do Tombo de los miembros y salarios de la capilla de doña Juana en Portugal (A.C. de Sousa Viterbo, "Jorge de Montemór", Archivo Histórico Portuguez, I, 8 (1903) 257-258, cf. Creel, op. cit., 49). Para Bryan Creel -que no precisa con qué ocupación se presenta a Montemayor en dicho documento- este dato es suficiente para probar que el poeta ejercía como cantor además de aposentador, pero extraña la ausencia de noticias sobre Montemayor en la "Nómina de los salarios de los oficiales y mugeres y criados de la casa de la Señora Princesa doña Juana, de los dos tercios segundo y postrero. Año de DLII" (Anglés, op. cit., 80) frente a la información que ahí se ofrece aclarando el destino de los demás cantores, que o bien sirvieron en Portugal o bien quedaron en España. Por otra parte, Sousa Viterbo también afirma -por una noticia que encontró en el archivo de la Torre do Tombo- que a Montemayor le concedieron el 14 de Marzo de 1551 la "escrevaninha de um dos navios da carreira da Mina, por uma viagem" (Sousa Viterbo, "Jorge de Montemor", 256, cf. F. Whyte, "Three Autos of Jorge de Montemayor", Publications of the Modern Languages Association, XLIII (1928) 953-989). No me ha sido posible consultar el artículo de Sousa Viterbo, pero el dato resulta incongruente con las fechas de la trayectoria de Montemayor en la Corte española y, de confirmarse, bien pudo ser alguna participación económica o un cargo del que no llegó a tomar posesión.
} 
Tuvo, señor, por bien de mi rudeza

Servir se, un bajo ser alevantando

Con su saber estraño i su grandeza, En cuia casa estoi ora, pasando

Con mi cansada musa ora en esto,

Ora de amor i ausencia estoy quejando,

Ora mi mal al mundo manifiesto;

Ora ordeno partir me, ora me quedo;

En una ora mil vezes mudo el puesto;

Ora, a hurto de Amor, me finjo ledo;

Ora me veo tan triste que me muero;

Ora querría morir me i nunca puedo.

Mil vezes me pregunto qué me quiero

I no sé responder me ni sentirme:

Enfin me hallo tal que desespero ${ }^{24}$.

Tales palabras no dejaron impasible a Francisco Sá de Miranda, quien en su respuesta a la desconsolada carta de Jorge de Montemayor intenta darle ánimos recordándole la dicha de residir en la Corte "al amparo" de la princesa española:

Levanta los sentidos al amparo

Tan seguro i tan alto, como tienes

De esta princesa nuestra, un sol tan claro;

No seas como muchos que sus bienes

Bien no conocen; mira que acontece

A pocos lo que a ti, si bien te avienes.

Io digo con tu suerte, que esclarece

Por la casa real en todo estado

Do, por costumbre antigua, envidia crece.

En fin las musas ternán cuidado

Del su poeta, que lo quieren tanto

Como a quien de años tiernos han criado.

$\mathrm{Al}$ son de sus vihuelas i al su canto

Lo entonan siempre, ve se clara prueva

Cantando él: mueve a gozo, mueve a llanto 25 .

Montemayor no oculta el descontento de su experiencia cortesana, y las causas pueden buscarse, más que en sus quejas por "amor i ausencia", en la frustración que le producía el propio ambiente de la corte, todo lo cual vivió mientras realizaba las funciones de cantor y de aposentador 26 .

\footnotetext{
${ }^{24}$ Michaelis de Vasconcelos, op. cit., 656-657.

25 Ibidem, 459-460.

${ }^{26} \mathrm{La}$ disconformidad que tenía Jorge de Montemayor con su posición en la Corte (y con la Corte misma), más allá del tópico del menosprecio de Corte y la alabanza de aldea, se agravará con el tiempo. Este hecho ya se advierte en los primeros versos de la mencionada epístola a Francisco Sá de Miranda, escrita durante su estancia portuguesa: "[Fortuna] Comigo se estrechó, i no se mueve/ a me subir a más que a un cierto grado/ i a me pasar de allí iamás se atreve". En el poema titulado Jorge de Montemayor contra el tiempo, el escritor hace la siguiente acusación: "El nescio es hoy admitido,/y de principes honrrado:/ pues triste del avisado/ que en este tiempo ha nascido:/sabéys lo
} 
La estancia de doña Juana en Portugal duró sólo dos años debido al fallecimiento repentino del príncipe portugués; y es muy probable que Montemayor regresara a España en Mayo de 1554 siguiendo a la joven viuda. Ella será quien gobierne el reino hasta el año 1559 en ausencia de su padre el Emperador y de su hermano Felipe, que ahora viajaba a Inglaterra para casarse con la reina María Tudor y en cuya comitiva pudo enrolarse el poeta.

Desconocemos por qué Jorge de Montemayor dejó de servir en la Casa de doña Juana ${ }^{27}$. Lo cierto es que los datos que poseemos sobre su ejercicio de la música como profesional se agotan en este punto y no es posible determinar si mantuvo algún compromiso oficial con la Casa Real española cuando presumiblemente se embarcó hacia Inglaterra. En cambio, se ha supuesto que para este viaje "quizá fuese en el séquito de alguno de los nobles que estuvieron en esa jornada, como Manrique de Lara, duque de Nájera y conde de Treviño, o Gonzalo Fernández de Córdoba, tercer duque de Sessa -dos prohombres con los que el escritor estuvo relacionado" 28 . Sea como fuere, Montemayor decide posteriormente seguir la carrera de las armas en busca de sus propias aspiraciones, abandonando la condición de criado en la Corte, como afirma Francisco López Estrada: "él pasó de músico de Corte a hidalgo. La transmutación se lleva a cabo mediante las armas, vía abierta en España a la ascensión social. Montemayor deja la Corte y toma la espada"29. Años más tarde en su opúsculo titulado Los Trabajos de los reyes (Amberes 1558) el poeta continuará lamentándose: "De mí sabré decir que ni han bastado X años de servicio con más miseria que abundancia, ni lo que en estas Armadas en su servicio he trabajado, para que su majestad se acuerde de despacharme" 30 .

que dél harán,/ aun que tenga más saber?/ que, o no terná que comer,/ o nescios le comerán" (Las obras de Ausias March, ed. cit., 325). Sobre el sentimiento anticortesano de Montemayor resulta muy interesante la epístola que escribe a Diego Ramírez Pagán, donde "la lenidad de la gente cortesana se muestra en sus varias apariencias: pretendientes, favoritos, aparentes dignidades, pleiteantes, ambiciosos, murmuradores, codiciosos, vanidad pomposa (52-81). Y hay un vicio al que ataca Montemayor por encima de todo: es la hipocresía, que lo lleva a la desesperación" (véase F. López Estrada, "La epístola de Montemayor a Diego Ramírez Pagán", en Estudios dedicados a Menéndez Pidal (Madrid, 1956) 387-406).

${ }^{27} \mathrm{La}$ causa pudiera estar en las relaciones del poeta con las corrientes espirituales reformistas y, en este sentido, interesa destacar

"su proximidad a doña Juana de Austria, figura de inquietudes religiosas reformadoras, de las que posteriormente tuvo que apartarse, al menos formalmente, con la implantación de las rígidas tesis del inquisidor Fernando de Valdés y su grupo de poder" (véase T. Ferrer Valls, "Bucolismo y teatralidad cortesana bajo el reinado de Felipe II", Voz y Letra, X/2, 1999, 10).

${ }^{28}$ La Diana, ed. cit., XXVIII, nota 1.

${ }^{29}$ F. López Estrada, "La Epístola de...”, op. cit., 404. Es bajo este contexto militar como se entienden las palabras de Montemayor recogidas por Fray Bartolomé Ponce en la carta dedicatoria al lector de la Primera Parte de la Clara Diana a lo divino (Zaragoza 1599), f. VI: "Con media risa me respondió Montemayor diziendo: Padre Ponce, hagan los frayles penitencia para todos, que los hijosdalgo armas y amores son su profesión" (cf. Los siete libros..., ed. cit., 17, nota 23).

30 Editado en F.J. Sánchez Cantón, "Los trabajos de los Reyes por Jorge de Montemayor", Revista de Filología Española, XII (1925) 45. 
En el periodo comprendido entre $1547 / 48$ y 1554 , durante su servicio en la Casa de las Infantas, Jorge de Montemayor va a coincidir con destacados músicos españoles. Compañero suyo fue un adolescente Mateo Flecha "el joven" (c.1530-1604), "moço de capilla" desde el año 1543 que después "quedó frayle francisco en Castilla" cuando doña Juana partió hacia Portugal ${ }^{31}$. Seguramente nuestro poeta conoció a Mateo Flecha "el viejo" (1481-1553), el famoso autor de ensaladas y tío de aquel, maestro de capilla de las Infantas desde 1544 hasta finales de 1548, sucediéndole en el puesto Bartolomé de Quevedo (c.1510-1569) ${ }^{32}$. También llegó a contar con la presencia de Pedro de Pastrana, el maestro de capilla del príncipe Felipe que, al no poder acompañarle en su viaje por Europa, permaneció en Valladolid sirviendo en la Casa de la princesa doña María hasta su regreso en $1551^{33}$.

Atendiendo al trato humano y artístico que pudo existir entre Montemayor y los músicos de la corte, habría que destacar, de entre todos los supuestos mencionados, la relación amistosa con el clavicordista Francisco de Soto, quien le complacería escribiendo un soneto laudatorio para "Las obras de George de Montemayor, repartidas en dos libros", título del Cancionero de $1554^{34}$.

\footnotetext{
${ }^{31}$ A pesar de lo que recoge el documento de Simancas (H. Anglés, op. cit., 81), lo cierto es que Mateo Flecha "el joven" ingresó en la orden carmelita y fue destinado a Valencia hasta el año 1564. Por esas fechas estuvo en Italia donde, debido a ciertas deudas con un noble romano, fue encarcelado por el provincial de los carmelitas de Lombardía. En Mayo de 1568 entró como maestro de capilla al servicio de Maximiliano II y de doña María en la corte imperial vienesa (R.L. Stevenson, La música en las catedrales españolas del Siglo de Oro (Madrid 1992) 358).

${ }^{32} \mathrm{La}$ laguna en las nóminas de la Casa de las Infantas para los años 1547/48 hace difícil precisar este punto (véase el estudio de J. Romeu Figueras, "Mateo Flecha el viejo, la Corte literario musical del duque de Calabria y el Cancionero llamado de Upsala", Anuario Musical, XIII (1958) 27). La sucesión de Mateo Flecha al frente de esta capilla fue atribuida en un principio a Bartolomé de Escobedo (c.1500-1563) por un malogrado baile de nombres en la lectura de los documentos del Archivo de Simancas (Anglés, op. cit., 80-81), pero tanto Jaime Moll como Robert Stevenson lo descartan expresamente en beneficio de Quevedo (véase J. Moll, "Libros de mùsica e instrumentos musicales de la princesa Juana de Austria", Anuario Musical, XX (1965) 9-10; también R.L. Stevenson, "Flecha, Mateo (i)" y "Quevedo, Bartolomé de", The New Grove Dictionary of Music and Musicians, ed. S. Sadie (Londres 1995)). Según Moll, Bartolomé de Quevedo pudo entrar al servicio de doña Juana en 1550 al morir el arzobispo de Santiago y Capellán Mayor del Emperador, Pedro Manuel, de cuya Casa era maestro de capilla. Al igual que Mateo Flecha "el joven", quedó en Castilla cuando la Infanta fue a Portugal. En 1553 consiguió el magisterio de la Catedral de Toledo.

${ }^{33}$ Pedro de Pastrana procedía de la corte valenciana del Duque de Calabria, a quien sirvió como maestro de capilla y del que recibió el nombramiento de abad del monasterio de San Bernardo. Había sido también capellán de Carlos V y como maestro de capilla del príncipe Felipe estuvo hasta fines de 1555, fecha quizá de su muerte (véase J. Romeu Figueras, op. cit., 68).

${ }^{34}$ Este Cancionero está dedicado en su primera parte a la princesa doña Juana y a su marido don Juan Manuel, presentándose Montemayor como "Criado de sus Altezas". La edición conocida se publicó en Amberes en 1554 pero es probable que hubiera otra anterior, quizá en Évora en 1553 (La Diana, ed. cit., XXIX). Su permiso de publicación es de Octubre de 1552, como demuestra N. Alonso Cortés (Los siete..., ed. cit., 14, nota 11). Se encuentra editado recientemente en Poesía completa, ed. cit..
} 


\title{
DE FRANCISCO DE SOTO, MUSICO DE CAMARA DE SU MAJESTAD, AL LECTOR soneto
}

\author{
Si gustas de graciosa montería, \\ lector, y te desseas emplear \\ do puedas sabiamente recrear \\ tu entendimiento más de cada día, \\ aquí verás la linda pradería \\ d'aquel Montemayor tan singular, \\ que a todo el mundo puede deleytar \\ su alto estylo y dulce melodía. \\ Aquí hallarás doctrina y devoción \\ con sentimientos tales que te mueva \\ a agradescer a Dios tu redempción. \\ Y los que de mortal amor se cevan \\ también verán en toda perfición \\ los dichos y hechos qu'ellos más apruevan.
}

Proveniente de la Casa de la emperatriz Isabel, el "músico de cámara y capilla" Francisco de Soto fue -a juicio de Higinio Anglés- el músico más valorado en la corte española, junto al organista Antonio de Cabezón. Ambos pasaron a servir la mitad del año en la Casa de las Infantas y la otra mitad en la Casa del príncipe Felipe para que pudieran atender por igual a los requerimientos musicales de los hijos de Carlos V. Como hiciera Jorge de Montemayor, estuvo sirviendo a la Infanta doña María en Valladolid y siguió también a doña Juana hasta Portugal en 1552 junto con su hijo, el organista Cipriano de Soto; pero, a diferencia de ellos, sin título para servir en la Casa portuguesa, por lo que volvió pocos meses más tarde al servicio del príncipe regente, una vez que hubo cumplido su cometido.

A propósito de la estancia en Portugal de algunos miembros de la capilla musical de la princesa doña Juana y atendiendo a la divulgación del repertorio para teclado, M. Santiago Kastner ha sugerido que mejor sería "lícito suponer una acción muy decisiva de parte de Cipriano de Soto y de Jorge de Montemayor en lo atañente a la difusión, en Portugal, del arte de Antonio de Cabezón"35.

Dentro de la escuela organística castellana del Renacimiento, el músico ciego Antonio de Cabezón (c.1510-1566) se alza como la figura más destacada. Su arte llegaría a ser conocido no sólo en Portugal, donde nunca llegó a estar -de ahí el interés de un contacto con Jorge de Montemayor-, sino en toda Europa gracias a que Felipe II, gran admirador de su música, insistió siempre en que le acompañara en sus desplazamientos. Una de aquellas

\footnotetext{
${ }^{35}$ M.S. Kastner, "Vestigios del arte de Antonio de Cabezón en Portugal", Anuario Musical, XXI (1966) 114. Sobre las obras de Francisco de Soto y de Cabezón incluidas en fuentes portuguesas, al lado de autores lusitanos como el conocido Heliodoro de Paíva, véase M.S. Kastner, "Los manuscritos musicales nº 48 y nº 242 de la Biblioteca General de la Universidad de Coimbra”, Anuario Musical, V (1950) 78 y ss.
} 
ocasiones fue la jornada que le llevó por Italia, Alemania y Flandes, iniciada a finales de 1548; y otra la boda con la reina de Inglaterra en $1554^{36}$.

\section{IV}

Es evidente que el caso del poeta y cantor portugués se enmarca bien en la realidad histórica del siglo XVI, con unas relaciones literarias y musicales entre España y Portugal fomentadas por múltiples vías, en especial por los acuerdos matrimoniales entre las familias Reales. Pero a ello habría que sumar el valor de su implicación artística en la corte española, con la que intentaría captar poco a poco las simpatías de su entorno, bien con sus dedicatorias literarias, bien con su presencia como músico ${ }^{37}$.

Una prueba de este protagonismo son tres piezas dramáticas incluidas en la sección religiosa de Las obras de 1554: los Autos [dedicados] al sereníssimo príncipe de Castilla. Fueron representados estos tres Autos de George de Montemayor en los Maytines de la noche de Navidad. A cada nocturno un Auto38; y también la noticia que nos muestra al poeta participando activamente en las fiestas que organizó la ciudad de Toro el 15 de Septiembre de 1551 para celebrar la entrada del príncipe Felipe, que visitaba a su hermana doña Juana: "y a la puerta de Santa Catalina le tenían hecho un arco triunfal muy triunfante, con muchos retratos y rétulos, y Montemayor arriba con un aucto muy gracioso, y el Corregidor, Regidores y escribanos con librea de carmesí y sus ropas hasta el suelo, para que jurase el Príncipe de obedecer los privilegios de la ciudad antes que entrase (...), al pasar de la puerta del mercado hubo otro arco triunfal con tanto aparato como el primero y con otro auto" 39 . Se advierte cierta afinidad entre el término "gracioso" y el tercer auto de

\footnotetext{
${ }^{36}$ Dada la continua movilidad de este organista, son pocas las ocasiones en que pudo coincidir con el autor de $L a$ Diana. En primer lugar, por una disposición real con fecha del 3 de Enero de 1548, Antonio de Cabezón dejó de servir a las Infantas para hacerlo exclusivamente en la Capilla del príncipe (M.S. Kastner, Antonio de..., op. cit., 189190). Tras regresar en 1551 del largo viaje por Europa y después de visitar a su familia en Ávila, donde participa como padrino en un bautizo el último día de Septiembre, recibe licencia el 8 de Junio de 1552 para ausentarse de la corte durante seis meses, la cual se retrasa hasta el día doce: "Antonio de Cabezón, músico tañedor de tecla, hebrero servió...[hasta] junio servió fasta doze de que se ausentó desta corte con licencia de su Alteza de seys meses que se cumplen en deziembre, en doze de diziembre deste año [1552]" (Véase H. Anglés, op. cit., 118 y M.S. Kastner, Antonio de..., op. cit., 231, 239-240). Si consideramos que Montemayor estaba ya en Portugal cuando vence esta licencia, la posibilidades de un encuentro entre los dos personajes se ve limitada a los primeros meses de servicio de Montemayor en la Casa de las Infantas, a las visitas que hará Felipe II a su hermana doña Juana en Toro en el año 1552 y, quizá, a las fechas del viaje a Inglaterra.
}

37 Sobre el interés de Montemayor por condescender al ambiente cortesano en el que se desenvolvía mediante la temática bucólica y el agasajo a sus protectores, véase T. Ferrer Valls, op. cit., 3-18.

38 Tanto la datación de los Autos como las circunstancias de su representación están aún por determinar. Florence White defiende que pudieron escribirse mucho antes de que fueran dedicados al príncipe Felipe y que la representación tuvo lugar en la Navidad de 1547 (White, op. cit., 958), descartando la Navidad del año 1551 al seguir el argumento de Sousa Viterbo que sitúa a Montemayor en Portugal en Marzo de ese mismo año (véase la nota 23 ).

39 "Relación de las fiestas que se hicieron en la ciudad de Toro en los desposorios de doña Juana, hija del Emperador Cárlos V, con el príncipe D. Juan de Portugal. Año 1552" (MS. en la Bibliot. particular de S.M. el Rey. Sala 2. Est.J. Plut.6, Tomo $4^{\circ}$ de Papeles varios), ed. en C. Fernández Duro, Memorias históricas de la ciudad de 
los incluidos en Las obras de 1554, donde se trata en clave de humor un casamiento "a lo divino", pero nada podemos asegurar. En cualquier caso, la anecdótica incursión dramática de Montemayor es especialmente interesante, pues debió de contar con la colaboración de los músicos de la corte -sus propios compañeros de Capilla- para el montaje de los cuadros musicales que precisan este tipo de representaciones ${ }^{40}$. Como hecho singular en la producción del poeta, los autos para "los Maytines de la noche de Navidad" bien podrían relacionarse con la especial afición que doña Juana tenía a las obras musicales destinadas al tiempo navideño (ensaladas, villancicos, chanzonetas), como declaran algunos biógrafos y demuestra el inventario de los bienes realizado a su muerte. No en balde, Jaime Moll llegó a observar cómo alrededor de la forma ensalada, en el segundo tercio del siglo XVI, se cerraba un exclusivo círculo de nombres que él veía relacionados entre sí directa o indirectamente. De esta forma, menciona a doña Juana de Austria, a Mateo Flecha "el viejo", a Bartomeu Cárceres, a Juan de Borja, a Mateo Flecha "el joven" y a Jorge de Montemayor ${ }^{41}$. Se podría insinuar, pues, que además de la tradición escénica recogida de Juan del Encina, Torres Naharro o el portugués Gil Vicente, nuestro poeta también tuvo como referencia las obras de Mateo Flecha "el viejo", sin duda el autor español más representativo del momento en lo atañente a la armonización de escenas propias de la Navidad y bajo cuya dirección tuvo ocasión de cantar en la capilla de las Infantas.

Es posible, en fin, que la relación de Jorge de Montemayor con ciertos músicos tras su paso por la capilla de las hijas de Carlos V dejase su impronta tanto en la historia de la música como en algunos de sus escritos (al menos ese sería el caso de los autos; su estudio desde este punto de vista y el seguimiento de otros ejemplos merecen la atención de una futura linea de investigación), lo que supondría un aspecto más a tener en cuenta en el análisis de la incidencia de la música en la obra de Montemayor y motivo suficiente para que la Musicología demuestre su interés por este poeta.

Así mismo, tampoco debe descartarse la posibilidad de que Montemayor entrara en contacto con otros músicos en España o en sus viajes por Europa. A propósito de la estancia de Montemayor en Valencia hacia 1558, debemos mencionar a Luís de Milán (1500-1561), autor del importante Libro de música de vihuela de mano intitulado El

Zamora, su provincia y obispado (Madrid 1882) 276-279. Dicha noticia se muestra creible si tenemos en cuenta que Montemayor aparece poco después como aposentador acompañando a la Infanta doña Juana hasta Portugal. Al mes siguiente don Felipe regresó a Madrid, pero estaba de nuevo en Toro cuando el 11 de Enero de 1552 tuvieron lugar los desposorios por poderes de su hermana con el príncipe portugués (volvería a visitarla en Abril y en Junio, antes de que doña Juana partiese para Lisboa el 24 de Octubre de ese año). Don Felipe pudo llegar con cierta antelación a los esponsales, la misma crónica nos informa que "todos los Grandes de España se hallaron en Toro, año de mil y quinientos y cincuenta y dos años, desde el primero día de Año Nuevo hasta las susodichas fiestas". De ser así, aún cabe la posibilidad de que Montemayor dedicara al príncipe los tres autos mencionados, no en el temprano año de 1547 , sino en la "noche de Navidad" del año 1551.

40 Entre los personajes que intervienen en los Autos dedicados al "sereníssimo príncipe de Castilla" se indica expresamente la presencia de "Cantores", lo cual no era extraño a la forma de este género. Véase B.W. Wardropper, Introducción al teatro religioso del Siglo de Oro: evolución del Auto Sacramental antes de Calderón (Salamanca 1967) 166-179.

41 J. Moll, op. cit., 18. 
Maestro (Valencia 1536), pues existe cierta semejanza entre el "Canto de Orfeo" de La Diana de Jorge de Montemayor y el elogio de las damas valencianas que hay en la jornada sexta de El Cortesano (Valencia 1561), tratado igualmente escrito por Milán que sigue los pasos de Il Cortegiano de Castiglione pero que es más una crónica de los festejos y diversiones de la corte del Duque de Calabria y de la alta sociedad valenciana que la frecuentaba ${ }^{42}$. También se ha apuntado el parecido existente entre un grabado que Milán incluye en El Maestro, donde se representa a Orfeo con una gran vihuela, y la descripción que Montemayor hace en su novela del mismo personaje: "Tenía vestida una cuera de tela de plata, guarnecida de perlas, las mangas le llegaban a medios brazos solamente y de allí adelante desnudos. Tenía unas calzas, hechas a la antigua, cortadas en la rodilla, de tela de plata, sembradas en ellas unas cítaras de oro; los cabellos eran largos y muy dorados, sobre los cuales tenía una muy hermosa guirnalda de laurel. En llegando a él las hermosas ninfas comenzó a tañer en una harpa que en las manos tenía muy dulcemente" 43 .

No quisiera terminar este artículo sin referirme propiamente a La Diana (Valencia 1558/1559), la obra más afamada de Jorge de Montemayor, donde las sugerencias musicales tienen su máximo exponente entre toda la producción literaria de aquel cantor de Corte que había dedicado a la música su "tiempo todo". Es cierto que tales indicaciones canoras forman parte de las claves propias del género bucólico, pero junto a su papel identificativo de los atributos pastoriles, la música, como artificio literario, trasciende aquí su función meramente descriptiva. El libro fue "concebido inicialmente (...) para satisfacción del público que formaban los caballeros y damas de la Corte" 44 y sus lectores no sólo gozarían del excelente discurso narrativo de Montemayor y de su inventiva poética sino que, junto a las idílicas imágenes que se evocaban, también sabrían recrear mentalmente los timbres instrumentales que reclamaba el autor para sus escenas, así como muchas de las melodías en que se fundamentaban aquellas canciones, pues estaban familiarizados con ellas ${ }^{45}$. Esta llamada al subconsciente musical del lector sería entonces otro medio para lograr lo que Juan Montero llama "la moción de los afectos", logrando, a mi juicio, reforzar aún más "la evidencia de la narración, a la que se llega mediante aquellos artificios que permiten al lector representarse la escena como si la estuviera viendo" 46 .

Precisamente por ser La Diana tan rica en referencias al arte de Orfeo no pasaría desapercibida entre los músicos. Se podría decir que la novela, con tanta variedad de canciones puestas en boca de pastores y ninfas, ofrecía una verdadera fuente de inspiración

\footnotetext{
42 Véase J. Romeu Figueras, op. cit., 55-79.

${ }^{43}$ La Diana, ed. cit., lib. IV, 185-186.

${ }^{44}$ La Diana, ed. cit., XLVII-XLVIII

45 Para las referencias musicales en La Diana puede ser de utilidad, aunque su análisis es bastante superficial y precisa de una revisión, el estudio de B.M. Damiani, Montemayor's "Diana". Music and Visual arts (Madison 1983).

${ }^{46}$ La Diana, ed. cit., LXXVII.
} 
musical en potencia de indudable atractivo para los compositores ${ }^{47}$. En este sentido es posible, incluso, que no se haya valorado bastante su influencia, siendo una de las obras más difundidas de la época. M.S. Kastner llegó a decir, a propósito de la elaboración que hacía de sus versos el poeta como melodía con acompañamiento instrumental, que la importancia de Montemayor para el ulterior desarrollo de los estilos musicales no debía subestimarse ${ }^{48}$. También se lamenta el insigne musicólogo de que no se haya conservado ninguna composición musical suya, pues sería de esperar que un espíritu tan elevado como el del portugués viese en la música un medio idóneo para expresarse.

Contamos, eso sí, con una hermosa muestra de versos de Jorge de Montemayor que han sido armonizados: son las piezas incluidas en el Cancionero musical de la Casa de Medinaceli, con textos de La Diana y música de Ginés de Morata, maestro de capilla de la Casa de Braganza ${ }^{49}$, sin duda un estimable y digno reconocimiento a la valía de su estilo literario y una prueba más de la amplia aceptación que su inmortal obra llegó a tener.

\footnotetext{
${ }^{47}$ Una particularidad de La Diana, reflejo del ambiente galante de palacio y del público al que va dirigido, es el "mosaico de poemas que se integran en la narración, algunos de los cuales pudieron ser originariamente cantados en reuniones literarias cortesanas, de las cuales las reuniones pastoriles no son más que una estilización (recordemos que Montemayor había sido cantor en palacio)" (T. Ferrer Valls, op. cit., 12).

${ }^{48}$ M.S. Kastner, Antonio de..., op. cit., 382.

${ }^{49}$ Se trata de "Ojos que ya no veis quien os mirava" y "Aquí me declaró su pensamiento" (Cancionero musical de la Casa de Medinaceli, Siglo XVI, ed. Miguel Querol (Barcelona 1949) 63-71). La Canción de Diana, de la que toman el texto (La Diana, ed. cit., lib. I, 27), es "una de las piezas del libro que tuvieron mayor difusión independiente; de hecho, se ha podido comprobar que ya era conocida antes de la impresión de la obra: el portugués Andrés de Resende realizó hacia 1552-1554 una versión latina del poema (...)" (La Diana, ed. cit., 27, nota 110).
} 